\title{
Maximal exercise testing in patients with spontaneous angina pectoris associated with transient ST segment elevation Risks and electrocardiographic findings
}

\author{
J.-M. R. Detry, P. Mengeot, M. F. Rousseau, J. Cosyns, R. Ponlot, and L. A. Brasseur \\ From the Cardio-Pulmonary Laboratory, Department of Medicine, Saint-Pierre University Hospital, Louvain, \\ Belgium
}

Six patients with spontaneous angina associated with transient ST segment elevation had a multistage maximal exercise (bicycle) test. In 5 patients, typical electrocardiographic changes were recorded during exercise, namely ST segment elevation often accompanied by an increase in the voltage of the $R$ wave and a widening of the QRS complex. Four of these patients developed severe rhythm disturbances: ventricular tachycardia (2 cases) and ventricular flutter (I case) were the reason for early interruption of the test in 3 patients, while $I$ patient had a short run of ventricular tachycardia after exercise. These rhythm disturbances which spontaneously regressed in all cases were consistently preceded by obvious ST elevation and in 2 patients were attended by slight chest discomfort.

Maximal exercise testing of patients suspected of variant angina provides important diagnostic information in many patients, but the risks of potentially lethal arrhythmias should be considered and resuscitation facilities should always be immediately available.

Transient ST segment elevation associated with spontaneous anginal pain is practically the only finding common to all cases reported as variant angina pectoris (Scherf and Cohen, 1974); simultaneously there is often an increase in the voltage of the $R$ waves, the $Q R S$ tends to become wider, and ventricular arrhythmias or atrioventricular conduction abnormalities are frequent (Prinzmetal et al., 1959, 1960; Lesbre et al., 1968; Jouve et al., 1969; Poggi et al., 1971; MacAlpin, Kattus, and Alvaro, 1973). Apart from these well-established electrocardiographic changes occurring with spontaneous angina pectoris, it is almost impossible to separate clearly the variant form of angina pectoris from the classical one (Scherf and Cohen, 1974).

In the variant form of angina pectoris, exercise is classically well tolerated though many patients have occasional episodes of pain while exercising (Robinson, 1965; Amichot and Jouve, 1970; Cosby et al., 1972; Cheng et al., 1973; Cherrier et al., 1973; Courtadon et al., 1973; MacAlpin et al., 1973).

Received 12 March 1975.
It has also been reported that in the variant form of angina, the exercise electrocardiogram was either normal or exhibited depression of the ST segment (Prinzmetal et al., 1959, 1960; Lesbre et al., I968; Amichot and Jouve, 1970); more recently, however, several authors have reported that the ST segment elevation commonly observed during the spontaneous episodes of anginal pain could also be precipitated by exercise testing, and at least 20 . such cases have been published (Robinson, 1965; Raynaud et al., 1969; Fortuin and Friesinger, 1970; Silverman and Flamm, 1971; Bobba et al., 1972; Cosby et al., 1972; Cheng et al., 1973; Cherrier et al., 1973; Courtadon et al., 1973; MacAlpin et al., 1973; Betriu, Solignac, and Bourassa, 1974; Bodenheimer et al., 1974).

We have observed 6 patients with spontaneous angina pectoris as a major complaint. When the electrocardiogram was recorded during spontaneous anginal pain, it displayed ST segment elevation accompanied by typical QRS changes; 4 of these patients also had occasional episodes of exertional angina pectoris. Maximal exercise testing 
TABLE Clinical data

\begin{tabular}{|c|c|c|c|c|c|c|c|c|c|}
\hline \multirow[t]{2}{*}{$\begin{array}{l}\text { Case } \\
\text { No. }\end{array}$} & \multirow[t]{2}{*}{$\begin{array}{l}\text { Age } \\
(y r)\end{array}$} & \multirow[t]{2}{*}{ Sex } & \multirow[t]{2}{*}{$\begin{array}{l}\text { Resting } \\
\text { electrocardiogram }\end{array}$} & \multicolumn{2}{|c|}{$\begin{array}{l}\text { Electrocardiogram during } \\
\text { spontaneous angina }\end{array}$} & \multicolumn{4}{|c|}{ Exercise test data } \\
\hline & & & & $S T$ segment changes & $\begin{array}{l}\text { QRS } \\
\text { changes }\end{array}$ & Pain & $\begin{array}{l}\text { Work- } \\
\text { load } \\
\text { (watts) }\end{array}$ & $\begin{array}{l}\text { Maximum } \\
H R\end{array}$ & $S T$ segment changes \\
\hline $\mathbf{I}$ & 58 & $\mathbf{M}$ & Normal & $3 \mathrm{~mm}$ rise II-III & Yes & No & 160 & 130 & $\begin{array}{l}2.5 \mathrm{~mm} \text { depression } \\
\mathrm{V}_{2}-\mathrm{V}_{5}\end{array}$ \\
\hline 2 & 47 & $\mathbf{M}$ & Normal & $\begin{array}{l}\text { 4-10 mm rise } \mathrm{VI}_{1}-\mathrm{V}_{5} \\
3 \text { mm depression } \\
\text { aVF-III }\end{array}$ & Yes & Yes & 120 & 124 & $\begin{array}{l}3 \mathrm{~mm} \text { rise } \mathrm{VI}_{\mathrm{I}}-\mathrm{V}_{3} \\
2 \mathrm{~mm} \text { depression } \\
\text { II-III }\end{array}$ \\
\hline 3 & $5 \mathrm{I}$ & $\mathbf{F}$ & Normal & $\begin{array}{l}2 \mathrm{~mm} \text { rise } \mathrm{VI}_{\mathrm{I}}-\mathrm{V}_{3} \\
2 \mathrm{~mm} \text { depression } \\
\text { II-III }\end{array}$ & No & Slight & 80 & 165 & $\begin{array}{l}5 \mathrm{~mm} \text { rise } \mathrm{VI}_{\mathrm{I}}-\mathrm{V}_{3} \\
\mathrm{I} \mathrm{mm} \text { depression } \\
\text { II-III }\end{array}$ \\
\hline 4 & 34 & $\mathbf{M}$ & $\begin{array}{l}\text { Flat T waves } \\
\text { II-III, V5-V6 }\end{array}$ & $5 \mathrm{~mm}$ rise $\mathrm{VI}_{-}-\mathrm{V}_{4}$ & Yes & Slight & 160 & 150 & 4-6 mm rise $\mathrm{VI}_{\mathrm{I}}-\mathrm{V}_{4}$ \\
\hline 5 & 45 & $\mathbf{M}$ & Normal & $3.5 \mathrm{~mm}$ rise $\mathrm{V}_{1}-\mathrm{V}_{3}$ & No & No & IIO & 155 & $\begin{array}{l}\text { 4-6 mm rise } \mathrm{V}_{4} \\
2 \mathrm{~mm} \text { depression } \\
\text { II-III }\end{array}$ \\
\hline 6 & 34 & $\mathbf{M}$ & $\begin{array}{c}\text { Biphasic } \\
T \text { waves } \\
V_{2}-V_{3}\end{array}$ & Not recorded & & No & 120 & 165 & $\begin{array}{l}6 \mathrm{~mm} \text { rise } \mathrm{VI}_{-}-\mathrm{V}_{3} \\
4 \mathrm{~mm} \text { depression } \\
\text { II-III }\end{array}$ \\
\hline
\end{tabular}

HR, heart rate; PVC, premature ventricular contraction; VT, ventricular tachycardia; VF, ventricular flutter; LAD, left anterior descending; RCA, right coronary artery.

induced ST segment elevation in 5 patients, while 4 patients also developed severe ventricular rhythm disturbances.

\section{Subjects and methods}

Six patients with spontaneous angina pectoris and no previous myocardial infarction have been studied. The clinical history of these patients is briefly described (see case reports) and the most relevant data are summarized in the Table.

The methods for exercise testing were as previously described (Detry et al., 197I; Rousseau, Brasseur, and Detry, 1973). Briefly, the subjects were asked to perform a multistage bicycle exercise test of maximally tolerated exercise with an initial workload of 50 watts and subsequent increments of 25 and 10 watts. Leads $V_{4}, V_{5}$, and V6 were monitored throughout and recorded on paper every minute; a I2-lead electrocardiogram was recorded at rest, after every 5 minutes of exercise, or more frequently if needed, at maximal exercise, and during recovery. Besides the appearance of typical anginal pain, the only criterion for interrupting the exercise test was the occurrence of 3 or more consecutive premature ventricular beats. Coronary angiography was performed using the method of Bourassa in 5 of the 6 patients (Lespérance, Bourassa, and Saltiel, 1970). Venous bypass grafting was proposed to 4 patients and performed in 3 .

\section{Case I}

\section{Case reports}

This 58-year-old man had frequent spontaneous anginal episodes during the day; his exercise tolerance was excellent and he played tennis regularly without any symptoms. During the spontaneous episodes, the electrocardiogram showed $3 \mathrm{~mm}$ ST elevation in II-III and a slight increase in the amplitude of the $R$ wave in III (from 9 to $14 \mathrm{~mm}$ ). The maximal exercise test was interrupted because of exhaustion and a 2.5 $\mathrm{mm}$ horizontal depression of the ST segment was recorded in V2 to V5 after exercise. Two months later the patient had an acute inferior myocardial infarction and he subsequently lost his angina.

\section{Case 2}

This 47-year-old man had spontaneous angina pectoris during the night for two months; each anginal episode was short but up to ro attacks would follow one after another. Exercise, even heavy, was usually well tolerated though the patient mentioned some episodes of exertional symptoms. During spontaneous pain, the electrocardiogram showed a 4 to $10 \mathrm{~mm} \mathrm{ST} \mathrm{segment}$ elevation from $V_{I}$ to $V_{5}$; in the same leads, the QRS was slightly prolonged ( $0.10 \mathrm{~s}$ ), and a moderate increase of the amplitude of the $R$ wave was noted (from 5 to $10 \mathrm{~mm}$ in V2). ST segment depression was present in the inferior leads.

The exercise test was interrupted for anginal pain and $3 \mathrm{~mm}$ ST segment elevation was observed in $V_{1}$ to $V_{3}$ where the voltage of the $T$ waves was increased $(20 \mathrm{~mm})$; reciprocal ST segment depression was noted in the leads II-III. The mean pulmonary arterial pressure rose from $16 \mathrm{mmHg}(2.1 \mathrm{kPa})$ at rest to $46 \mathrm{mmHg}$ (6.I $\mathrm{kPa})$ during pain. Occasional 
Angiographic data

\begin{tabular}{|c|c|}
\hline $\begin{array}{l}\text { QRS } \\
\text { changes }\end{array}$ & $\begin{array}{l}\text { Rhythm } \\
\text { disturbances }\end{array}$ \\
\hline No & No \\
\hline No & $\begin{array}{l}\text { Occasional } \\
\text { PVCs }\end{array}$ \\
\hline Yes & VT \\
\hline Yes & VT \\
\hline Yes & $\begin{array}{c}\text { Frequent } \\
\text { PVCs } \\
\text { and VF } \\
\text { VT }\end{array}$ \\
\hline Yes & VT \\
\hline
\end{tabular}

\section{Case 3}

This 5I-year-old woman had exertional and mostly spontaneous angina pectoris for one month. Several episodes of spontaneous pain were observed in the coronary care unit: a $2 \mathrm{~mm}$ ST segment rise was consistently noted in Vr to $V_{3}$ while there was $2 \mathrm{~mm}$ ST segment depression in the inferior leads.

During exertion, the QRS complex became wider (from 0.07 to $0.10 \mathrm{~s}$ in $\mathrm{V}_{5}$ ) and a $5 \mathrm{~mm}$ elevation of the $S T$ segment was noted in $V_{1}$ to $V_{3} ; 30$ seconds later, the test was interrupted at 80 watts because of exhaustion (HR: 165/min) attended by slight chest discomfort. A few seconds later, a short episode of ventricular tachycardia unsuspected by the patient was recorded (Fig. I); a I mm depression of the ST segment was observed at the third minute of the recovery in II, III, and $\mathrm{V}_{4}$ to V6. A second exercise test performed one month later caused the same electrocardiographic changes, including the ventricular tachycardia.

The coronary arteries were normal, while ventriculography demonstrated a small dyskinetic zone at the apex. During the 15-month follow-up, the anginal syndrome remained unchanged but the patient reported two syncopal episodes not preceded by chest pain; neurological examination was normal and we suspect that these episodes might be caused by transient severe ventricular arrhythmias.

\section{Case 4}

During the previous 6 months this 34-year-old man had frequent and disabling episodes of spontaneous nocturnal angina; his exercise tolerance was usually normal but he also reported a few episodes of exertional chest pain. During spontaneous angina pectoris the electrocardiogram showed a $5 \mathrm{~mm}$ ST segment rise from VI to V4, with a widened QRS complex (from 0.07 to $0.10 \mathrm{~s}$ ) and an increased $R$ wave (from 10 to $21 \mathrm{~mm}$ ); at that because of exhaustion at 195 watts (HR: $165 / \mathrm{min}$ ) and the exertional electrocardiogram was normal.

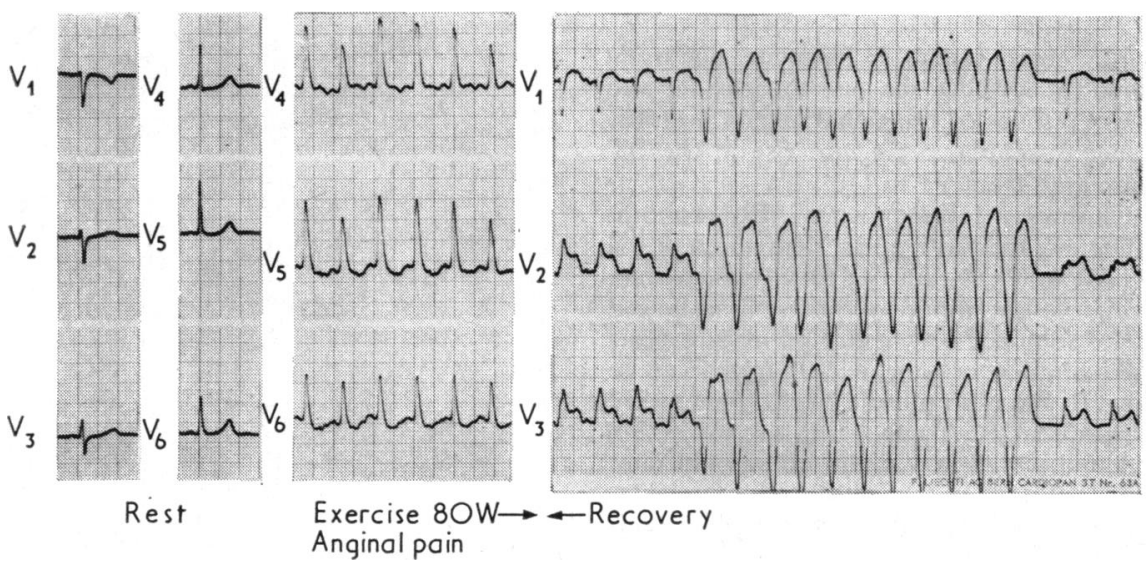

FIG. I Case 3. Electrocardiogram recorded at rest, at maximal exercise, and during the first seconds of recovery. 


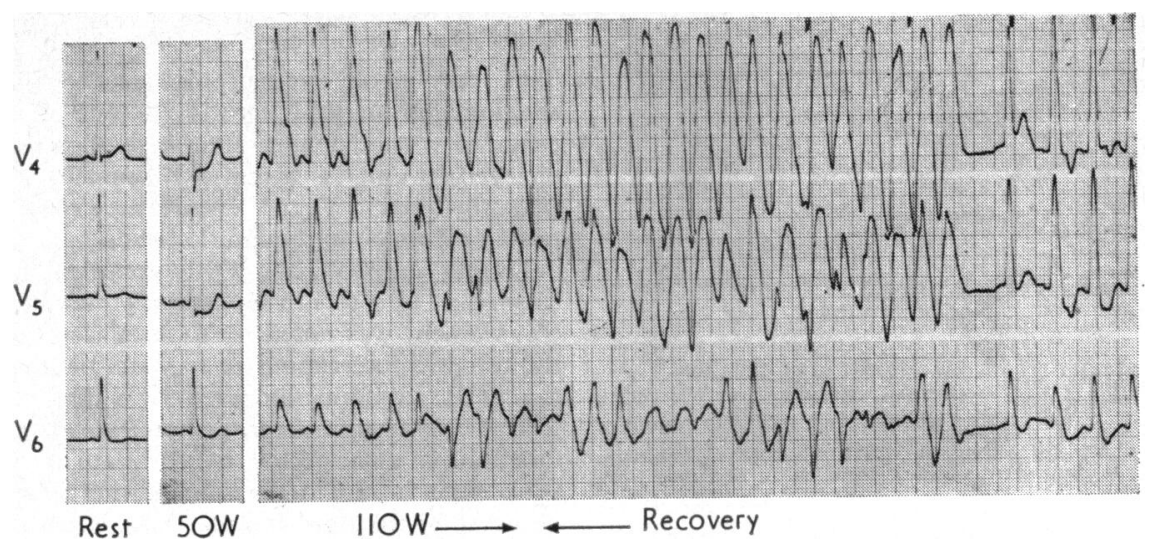

FIG. 2 Case 5. Electrocardiogram recorded at rest, during submaximal exercise, and at the end of the test which was interrupted because of the onset of ventricular flutter; this rhythm disturbance with alternating ventricular complexes may be lbetter described as 'torsade de pointes' (Desertenne, 1966).

time the mean pulmonary arterial pressure rose from 17 to $32 \mathrm{mmHg}$ (2.3 to $4.3 \mathrm{kPa}$ ).

At the 5 th minute of the exercise test an increase in $R$ wave voltage (from 16 to $30 \mathrm{~mm}$ ) and a slight widening of the QRS complex (from 0.08 to $0.10 \mathrm{~s}$ ) were noted; they were followed by the appearance of a 4 to $6 \mathrm{~mm}$ rise in the ST segment from VI to $\mathrm{V}_{4}$. The exercise test was interrupted one minute later at 160 watts because of the occurrence of two consecutive short runs of ventricular tachycardia; at that time the patient reported minor chest discomfort but no dizziness.

Coronary angiography revealed an isolated proximal 70 per cent stenosis of the left anterior descending artery and a venous bypass operation was performed; all spontaneous anginal crises disappeared, but to days after operation the patient died from acute and massive pericardial bleeding.

\section{Case 5}

This 45-year-old man reported frequent nocturnal spontaneous anginal episodes for one month; he also mentioned a few episodes of exertional angina pectoris. During spontaneous angina, a $3.5 \mathrm{~mm}$ rise in the ST segment was observed from VI to V3.

At submaximal exercise level ( 75 watts; $H R$ : $110 / \mathrm{min}$ ) the electrocardiogram showed a $2 \mathrm{~mm}$ depression of the ST segment in $V_{3}$ to $V_{5}$. Leads $V_{4}$ to $V_{6}$ which were monitored during the last minute of the test first showed the appearance of frequent ventricular premature beats while the QRS complex became wider (from 0.06 to $0.11 \mathrm{~s}$ ) and the $R$ wave amplitude slightly increased (from 25 to $35 \mathrm{~mm}$ in V4). A 4 to $6 \mathrm{~mm}$ rise in the ST segment was then observed in $\mathrm{V}_{4}$, and 30 seconds later the test was interrupted at the onset of ventricular flutter which disappeared spontaneously after 5 seconds (Fig. 2); a second short episode of ventricular flutter occurred a few seconds later. The patient had no anginal pain and he remained unaware of his rhythm disturb- ance. At the fifth minute of recovery a $2 \mathrm{~mm} \mathrm{ST} \mathrm{seg-}$ ment depression was noted in leads II, III, V5, and V6.

The coronary angiograms revealed a localized 90 per cent stenosis of the left anterior descending artery, and

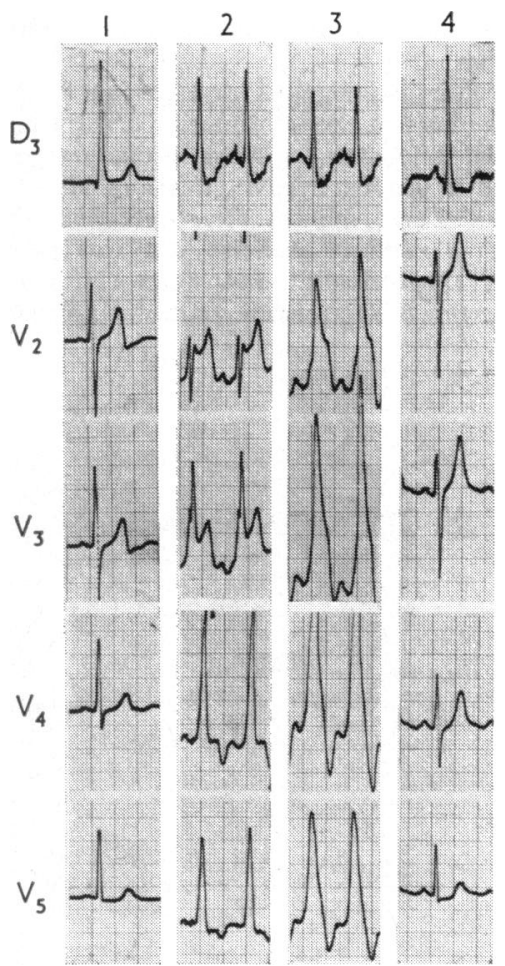

FIG. 3 Case 6. Electrocardiogram: 1) at rest; 2) during submaximal exercise; 3) at maximal exercise; 4) at the 5th minute of recovery. 
this lesion was bypassed with a saphenous vein graft. All the symptoms have disappeared and a 3-month postoperative angiographic study demonstrated patency of the graft. A maximal exercise test caused a I mm horizontal depression of the ST segment in lead V5.

\section{Case 6}

This 34-year-old man had frequent nocturnal spontaneous angina over a period of 8 months; he regularly undertook heavy exercise without symptoms. We never had a chance to record an electrocardiogram during a spontaneous episode of chest pain.

During the exercise test ST segment elevation was observed in leads $V_{1}$ to $V_{3}$, while the ST segment became depressed in the inferior leads (Fig. 3); the duration of the QRS complex increased from 0.06 to $0.10 \mathrm{~s}$, and the amplitude of the $R$ wave increased from 19 to $38 \mathrm{~mm}$ in $\mathrm{V}_{4}$. The exercise test was interrupted 2 minutes later because of exhaustion at a workload of I20 watts; the QRS and the ST segment were then merged into a single giant wave. During early recovery, the patient had a short run of ventricular tachycardia ( 5 consecutive premature ventricular beats). These abnormalities slowly regressed and ST segment depression was still noted in V5, II, and III five minutes after the end of the exercise test.

The coronary angiograms demonstrated an isolated proximal 80 per cent stenosis of the left anterior descending artery; the projected bypass procedure was refused by the patient. Two months later he had an anteroseptal acute myocardial infarction and lost his anginal syndrome; he has now been symptomless for 22 months.

\section{Discussion}

All the patients described in the present paper were referred to the hospital for spontaneous angina pectoris and the electrocardiogram recorded during the pain showed QRST changes similar to those initially described by Prinzmetal et al. (1959, 1960). Since 4 patients also had occasional episodes of anginal pain with exertion, our group may not really be comparable to the cases previously reported as having the variant form of angina pectoris though the variability of this syndrome is recognized (Scherf and Cohen, 1974).

In 5 of the 6 patients, exercise testing caused QRST changes similar to those usually observed during spontaneous episodes of angina: in 4 of these patients (Cases 2, 3, 4, and 5), the exertional ST changes were observed in the same leads as during spontaneous pain and the reciprocal ST segment depression was also similar in 3 patients. Changes in the QRS complex were common during exercise (Cases 3, 4, 5, and 6) even when they had not been observed during spontaneous anginal episodes. The high incidence $(5 / 6)$ of these typical electrocardiographic abnormalities with exercise contrasts with previous reports claiming that in the variant form of angina pectoris, exercise tests were of little value, the exercise electrocardiogram being either normal or showing only ST segment depression; unfortunately the number of patients tested, the methods of testing, and the results of all exercise tests are not mentioned in these reports (Prinzmetal et al., 1959, 1960; Lesbre et al., 1968; Amichot and Jouve, 1970). Our data together with those previously reported indicate that ST segment elevation with exertion is a common finding in the variant form of angina pectoris (Robinson, 1965; Raynaud et al., 1969; Fortuin and Friesinger, 1970; Silverman and Flamm, 1971; Bobba et al., 1972; Cosby et al., 1972; Cheng et al., 1973; Cherrier et al., 1973; Courtadon et al., 1973; MacAlpin et al., 1973; Betriu et al., 1974; Bodenheimer et al., 1974); the true incidence of these electrocardiographic abnormalities with exercise is, however, difficult to evaluate from previous reports, since many patients were observed only in coronary care units and had no exercise tests.

A second reason for the high incidence of ST segment elevation with exercise in our patients might be the recording of a 12-lead electrocardiogram during exercise. The ST segment abnormalities were always recorded in leads $\mathrm{VI}_{1}$ to $\mathrm{V}_{4}$; these leads are sometimes neglected and ST segment elevation would have been overlooked if V5 only had been used for monitoring the test. This methodological aspect could account for the lower incidence of ST changes recently reported by MacAlpin et al. (1973). A third likely explanation for our data is the use of a maximal exercise testing procedure which in the classical form of angina pectoris greatly enhances the diagnostic sensitivity of the test (Sheffield, Holt, and Reeves, 1965; Mason et al., 1967; Detry, 1973).

The exercise test induced severe ventricular rhythm disturbances in 4 of the 6 patients. These ventricular arrhythmias were always preceded by obvious ST elevation for 30 seconds to 2 minutes and were accompanied by a slight chest discomfort in 2 patients; the ventricular arrhythmias did not cause dizziness or syncope and they were all spontaneously reversible. It is noticeable that the ventricular arrhythmias occurred only in those patients who reached a heart rate of $150 / \mathrm{min}$ or more. Four similar cases have been previously reported: in 3, the ventricular tachycardia was preceded or followed by exertional ST segment rises (Raynaud et al., 1969; Cherrier et al., 1973) while in I case, the ventricular tachycardia was preceded by ST segment depression (Bodenheimer et al., 1974).

This incidence of severe ventricular rhythm 
disturbances precipitated by exercise is in striking contrast to their rarity in the presence of classical coronary heart disease (Ellestad et al., 1969; Rochmis and Blackburn, 1971) even when exertion caused ST segment rises (Fortuin and Friesinger, 1970). Such ventricular arrhythmias are, however, not uncommon in variant angina pectoris since during the episodes of spontaneous angina, 40 per cent of the patients develop atrioventricular conduction abnormalities or arrhythmias (Lesbre et al., 1968; Poggi et al., 1971 ; MacAlpin et al., 1973); these are most often noted when the pain is intense and/or the ST segment rise is striking. Our results are possibly related to the fact that the exercise tests were continued until exhaustion, angina pectoris, or onset of a ventricular arrhythmia, despite the appearance of ST segment rises which gradually increased; such ST segment elevation reflects a severe degree of myocardial ischaemia (Ekmekci et al., 196I) and is often considered as a criterion for early interruption of a diagnostic exercise test (Rochmis and Blackburn, 1971).

The varying $Q R S$ axes during the ventricular rhythm disturbance (Fig. 2) strongly suggest that it is a 'torsade de pointes'1 rather than a ventricular flutter (Desertenne, I966; Motte et al., 1970; Krikler, 1974); this observation suggests a new cause for 'torsade de pointes', namely an exerciseinduced subepicardial injury current.

The mechanism responsible for the electrocardiographic changes precipitated by exercise in our patients with the variant form of angina are not known, but their similarity to the electrocardiographic abnormalities observed during spontaneous attacks implies a similar mechanism; Prinzmetal et al. (1959, 1960) suggested that transient coronary arterial spasm could account for most characteristics of the syndrome, and such spasm has now been demonstrated angiographically both in patients with coronary lesions (Dhurandhar et al., 1972; Gonin et al., 1973; MacAlpin et al., 1973) and in patients with normal coronary arteries (Cheng et al., 1973; Froment, Normand, and Amiel, 1973; Oliva, Potts, and Pluss, 1973; Betriu et al., 1974; Kerin and Macleod, 1974). The true role of spasm in the pathophysiology of variant angina pectoris remains to be firmly established and it is not known whether or not it can account for the electrocardiographic abnormality during exercise. If one postulates that spasm is involved in the response to exercise, then myocardial hypoxia could itself

\footnotetext{
${ }^{1}$ A form of ventricular tachycardia characterized by twisting alteration in the QRS morphology; it is usually induced by a ventricular extrasystole occurring late in the cycle, in patients who have underlying bradycardia or QT prolongation; it may cause syncope and lead to ventricular fibrillation.
}

be a triggering factor, since ST segment rises similar to those reported here with exercise have also been precipitated by atrial pacing (Cheng et al., 1973; Gonin et al., 1973; Betriu et al., 1974) and by arterial hypoxia (Bekaert, Afschrift, and De Tollenaere, 197I; Cherrier et al., 1973).

We conclude that maximal exercise testing of patients suspected of variant angina pectoris often provides important diagnostic information. The risks of testing these patients are much greater than usually believed since severe ventricular arrhythmias frequently occur.

This investigation was supported by grants from the 'Fonds de la Recherche Scientifique Medicale' and the 'Commission des Communatés Européennes'.

\section{References}

Amichot, J. L., and Jouve, A. (1970). Une forme inhabituelle d'angor spontané. L'angor dit de Prinzmetal. Médecine et Hygiene, 28, 984.

Bekaert, S., Afschrift, M., and de Tollenaere, G. (1971). Angor van Prinzmetal. Acta Clinica Belgica, 26, 228.

Betriu, A., Solignac, A., and Bourassa, M. G. (1974). The variant form of angina. Diagnostic and therapeutic implications. American Heart fournal, 87, 272.

Bobba, P., Vecchio, C., Di Guglielmo, L., Salerno, J., Casari, A., and Montemartini, C. (1972). Exercise-induced RS-T elevation. Electrocardiographic and angiographic observations. Cardiology, 57, 162.

Bodenheimer, M., Lipski, J., Donoso, E., and Dack, S. (1974). Prinzmetal's variant angina. A clinical and electrocardiographic study. American Heart fournal, 87, 304.

Cheng, T. O., Bashour, T., Kelser, G. A., Weiss, L., and Bacos, J. (1973). Variant angina of Prinzmetal with normal coronary arteriograms. A variant of the variant. Circulation, $47,476$.

Cherrier, F., Culliere, M., Dodinot, B., and Hua, G. (1973). Angor de Prinzmetal; aspects coronarographiques; considérations thérapeutiques. A propos de 7 observations. Archives des Maladies du Coeur et des Vaisseaux, 66, 579.

Cosby, R. S., Giddings, J. A., See, J. R., and Mayo, M. (1972). Variant angina. Case reports and critique. American fournal of Medicine, 53, 739.

Courtadon, M., Jourde, M., Alix, B., Brivady, A., Viallet, J. F., and Jallut, H. (1973). Modifications électrocardiographiques de type 'Prinzmetal' provoquées par épreuve d'effort; à propos de 2 cas. Coeur, $4,729$.

Desertenne, F. (1966). La tachycardie ventriculaire à deux foyers opposés variables. Archives des Maladies du Coeur et des Vaisseaux, 59, 263.

Detry, J. M. R. (1973). Exercise Testing and Training in Coronary Heart Disease. Ed. Stenfert-Kroese, Leiden.

Detry, J. M. R., Rousseau, M., Vandenbroucke, G., Kusumi, F., Brasseur, L. A., and Bruce, R. A. (197I). Increased arteriovenous oxygen difference after physical training in coronary heart disease. Circulation, 44, 109.

Dhurandhar, R. W., Watt, D. L., Silver, M. D., Trimble, A. S., and Adelman, A. G. (1972). Prinzmetal's variant form of angina with arteriographic evidence of coronary arterial spasm. American fournal of Cardiology, 30, 902.

Ekmekci, A., Toyoshima, H., Kwoczynski, J. K., Nagaya, T., and Prinzmetal, M. (I96I). Angina pectoris. IV. Clinical and experimental difference between ischemia with 
S-T elevation and ischemia with S-T depression. American fournal of Cardiology, 7, 412.

Ellestad, M. H., Allen, W., Wan, M. C. K., and Kemp, G. L. (1969). Maximal treadmill stress testing for cardiovascular evaluation. Circulation, 39, 517.

Fortuin, N. J., and Friesinger, G. C. (1970). Exercise-induced S-T segment elevation. Clinical, electrocardiographic and arteriographic studies in twelve patients. American fournal of Medicine, 49, 459.

Froment, R., Normand, J., and Amiel, L. (1973). Angine de poitrine du type Prinzmetal. Coronaires perméables, mais spasme de l'interventriculaire antérieure en cours de crise. Archives des Maladies du Coeur et des Vaisseaux, 66, 755.

Gonin, A., Berthou, J. D., Delaye, J., Roques, J. C., Touboul, P., and Janin, A. (1973). Angor de Prinzmetal: apporte de la coronarographie et discussion de la chirurgie de revascularisation (à propos de 13 cas comportant 10 coronarographies sélectives et 9 pontages aortocoronariens). Archives des Maladies du Coeur et des Vaisseaux, 66, 571 .

Jouve, A., Guiran, J. B., Viallet, H., Gras, A., Blanc, M., Arnoux, M., Rouvier, M., and Brunel, J. C. (1969). Les modifications électrocardiographiques au cours des crises d'angor spontané. A propos de la forme décrite par Prinzmetal. Archives des Maladies du Coeur et des Vaisseaux, 62, 331.

Kerin, N., and Macleod, C. A. (1974). Coronary artery spasm associated with variant angina pectoris. British Heart Fournal, 36, 224.

Krikler, D. M. (1974). A fresh look at cardiac arrhythmias. Pathogenesis and presentation. Lancet, I, 913.

Lesbre, J. P., Ane, M., Salvador, M., Bounhoure, J. P., Duboucher, G., Mignon, J. P., and Meriel, P. (I968). L'angor de Prinzmetal. Annales de Cardiologie et d'Angéiologie, 17, 215.

Lespérance, J., Bourassa, M. G., and Saltiel, J. (1970). La cinécoronarographie sélective par voie fémorale percutanée. Annales de Radiologie, 13, 55.

MacAlpin, R. N., Kattus, A. A., and Alvaro, A. G. (1973). Angina pectoris at rest with preservation of exercise capacity. Circulation, 47, 946.

Mason, R. E., Likar, I., Biern, R. O., and Ross, R. S. (1967). Multiple-lead exercise electrocardiography. Experience in I07 normal subjects and 67 patients with angina pectoris, and comparison with coronary cinearteriography in 84 patients. Circulation, 36, 517.
Motte, G., Coumel, P., Abitbol, G., Desertenne, F., and Slama, R. (1970). Le syndrome QT long et syncopes par 'torsades de pointe'. Archives des Maladies du Coeur et des Vaisseaux, 63, 831.

Oliva, P. B., Potts, D. E., and Pluss, R. G. (1973). Coronary arterial spasm in Prinzmetal angina. New England fournal of Medicine, 288, 745.

Poggi, L., Bory, M., Djiane, P., Chabaud, R., Sebaoun, E., and Serradimigni, A. (1971). Les troubles du rythme au cours des crises d'angor spontané de Prinzmetal. Archives des Maladies du Coeur et des Vaisseaux, 64, 874.

Prinzmetal, M., Ekmecki, A., Kennamer, R., Kwoczynski, J. K., Shubin, H., and Toyoshima, H. (1960). Variant form of angina pectoris. Previously undelineated syndrome. Fournal of the American Medical Association, 174, I794.

Prinzmetal, M., Kennamer, R., Merliss, R., Wada, T., and Bor, N. (1959). Angina pectoris. I. A variant form of angina pectoris. Preliminary report. American fournal of Medicine, 27, 375.

Raynaud, R., Brochier, M., Morand, Ph., Fauchier, J. P., Raynaud, P., and Chatelain, B. (1969). Une forme clinique de l'angine de poitrine: l'angor de Prinzmetal. Semaine des Hôpitaux de Paris, 45, 2662.

Robinson, J. S. (1965). Prinzmetal's variant angina pectoris. Report of a case. American Heart fournal, 70, 797.

Rochmis, P., and Blackburn, H. (1971). Exercise tests: a survey of procedures, safety, and litigation experience in approximately 170,000 tests. Fournal of the American Medical Association, 217, 1061.

Rousseau, M. F., Brasseur, L. A., and Detry, J. M. R. (1973). Hemodynamic determinants of maximal oxygen intake in patients with healed myocardial infarction: influence of physical training. Circulation, 48, 943.

Scherf, D., and Cohen, J. (1974). 'Variant' angina pectoris. Circulation, 49, 787.

Sheffield, L. T., Holt, J. H., and Reeves, T. J. (1965). Exercise graded by heart rate in electrocardiographic testing for angina pectoris. Circulation, 32, 622 .

Silverman, M. E., and Flamm, M. D. (197I). Variant angina pectoris. Anatomic findings and prognostic implications. Annals of Internal Medicine, 75, 339.

Requests for reprints to Dr. J.-M. R. Detry, CardioPulmonary Laboratory, Cliniques Universitaires St. Pierre, 69 Brusselsestraat, B - 3000 Leuven, Belgium. 